\title{
Survey on the treatment of non-small cell lung cancer (NSCLC) in England and Wales
}

\author{
A. Crook*, A. Duffy*, D.J. Girling*, R.L. Souhami**, M.K.B. Parmar*
}

Survey on the treatment of non-small cell lung cancer (NSCLC) in England and Wales. A. Crook, A. Duffy, D.J. Girling, R.L. Souhami, M.K.B. Parmar. CERS Journals Ltd 1997.

ABSTRACT: As an adjunct to a meta-analysis of chemotherapy for non-small cell lung cancer (NSCLC), a survey was conducted in England and Wales of clinicians' views on the role of chemotherapy in NSCLC and the benefits it would have to offer to lead them to change their practice.

Radiotherapists, medical oncologists, surgeons and physicians specializing in thoracic medicine, and physicians of palliative medicine were asked their views on the treatment of three case histories of $65 \mathrm{yr}$ old men: Case 1, resected tumour involving a hilar lymph node (tumour (T)2, node (N)1, metastasis (M)0); Case 2, tumour that had spread to mediastinal lymph nodes bilaterally (T2, N3, M0); and Case 3, metastatic cancer (M1) accompanied by minor haemoptysis.

Six hundred and ninety eight $(85 \%)$ of the 821 clinicians responded. For Case $1,74 \%$ would not recommend any adjuvant treatment, $24 \%$ would recommend radiotherapy, and $<1 \%$ chemotherapy, and there was little expectation that adjuvant treatment would improve survival. For Case $2,68 \%$ would recommend radiotherapy, $11 \%$ chemotherapy, and $1 \%$ surgery, $7 \%$ recommending a combination. Adjuvant treatment, regardless of modality, was expected to improve survival. For Case 3, only $11 \%$ would recommend chemotherapy, but $26 \%$ if the patient was aged $\leq \mathbf{5 0}$ yrs. There was little expectation of survival beyond $1 \mathrm{yr}$, or of improving survival with chemotherapy. For all three cases, most of those not recommending chemotherapy would require it to achieve substantially improved survival for them to use it routinely.

Surgery alone is currently considered sufficient for resectable non-small cell lung cancer. Chemotherapy is rarely recommended for disease of any stage. Eur Respir J 1997; 10: 1552-1558.

\begin{abstract}
*Medical Research Council Cancer Trials Office, Cambridge, UK. **Dept of Oncology, Middlesex Hospital, London, UK.
\end{abstract}

Correspondence: D.J. Girling MRC Cancer Trials Office

5 Shaftesbury Road

Cambridge CB2 2BW

UK

Keywords: Chemotherapy multi-modality treatment non-small cell lung cancer radiotherapy

treatment survey

Received: December 301996 Accepted after revision April 141997
The primary treatment of choice for patients with nonsmall cell lung cancer (NSCLC) is surgical resection with curative intent, although there is much debate about the local extent of disease that should be regarded as potentially curable by this means [1-4], and less than $30 \%$ of patients present for treatment with potentially resectable disease. For inoperable, nonmetastatic disease, radiotherapy to the thorax is likely to be considered. Some patients will be deemed suitable for radical radiotherapy, but in the majority, advanced disease within the chest or metastatic disease will preclude potentially curative treatment. For these patients, palliative radiotherapy may be considered, or supportive care alone $[5,6]$.

In spite of a large number of randomized trials, there remains substantial disagreement, both nationally and internationally, about whether chemotherapy should be given in addition to any of the above primary treatments [7-10]. In the UK, it is currently recommended only within research protocols or under careful supervision by accredited cancer specialists [11]. In 1992, a collaborative meta-analysis was initiated by the British Medical Research Council (MRC), the Institut Gustave Roussy in France, and the Istituto di Richerche Farmaco- logiche "Mario Negri" in Italy, to establish whether there was reliable evidence that chemotherapy improved the survival of patients with NSCLC [12]. The meta-analysis was based on updated individual patient data from all published and unpublished randomized trials making an unconfounded comparison of primary treatment versus primary treatment plus chemotherapy. The comparison was made for the four primary treatments: surgery; surgery plus radiotherapy; radical radiotherapy; and supportive care.

As an adjunct to this meta-analysis, a survey of clinicians treating lung cancer was undertaken to determine their views on the current role of chemotherapy, in particular, how they would manage three clinical situations given in three case histories, to ascertain their opinion on the likely efficacy of chemotherapy, and what benefits from it would be required for them to change their practice. This project was initiated by the National Cancer Institute of Canada; the same questionnaire has been applied in Canada, France, and Italy, as well as in England and Wales. The results from Canada have already been published [13]. The present paper reports the results in England and Wales. 


\section{Methods}

\section{Target population}

Lists of consultant radiotherapists, medical oncologists, cardiothoracic and thoracic surgeons, thoracic physicians, general physicians with a special interest in thoracic medicine, and physicians of palliative medicine in England and Wales were obtained from the Royal College of Physicians of London, the Society of Cardiothoracic Surgeons, and the Royal College of Radiologists. During July and August 1993, the clinicians were sent the questionnaire, a letter explaining its purpose and drawing attention to its international dimension, and a stamped addressed envelope for its return. Four and eight weeks after the first mailing, a reminder was sent to clinicians who had not yet responded. Clinicians who still failed to respond, were then telephoned and encouraged to respond and, if necessary, were sent a further copy of the questionnaire.

\section{The questionnaire}

The questionnaire was in four sections. The first three related to three case histories; the fourth requested information about the respondent. The case histories were of common clinical presentations of NSCLC with controversial treatment options. Respondents were asked to complete the questionnaire only for those types of patients that they themselves treated.

The first case history described a $65 \mathrm{yr}$ old man with a completely resected squamous cell tumour, involving a hilar lymph node: tumour $(\mathrm{T}) 2$, node $(\mathrm{N}) 1$, metastasis (M)0 classification of disease. Respondents were asked whether, at the first follow-up attendance, when the patient was well and symptom-free, they would recommend no further treatment, chemotherapy, radiotherapy, or other treatment, to be specified. They were asked the probability, in their opinion, of the patient being alive in 5 yrs: without adjuvant therapy; with adjuvant chemotherapy; with adjuvant radiotherapy; and with both chemotherapy and radiotherapy. If they did not recommend chemotherapy, they were asked what $5 \mathrm{yr}$ survival rate would have to be achieved in this type of patient for them to adopt such treatment routinely.

The second case history involved a $65 \mathrm{yr}$ old man with a squamous cell tumour that had spread to mediastinal lymph nodes bilaterally: T2, N3, M0 disease. Respondents were asked whether they would recommend: no specific anticancer treatment at that stage; thoracic radiotherapy; chemotherapy; surgery; or some other treatment, to be specified. Responses were not required to be mutually exclusive. They were asked their views on either the probability of the patient being alive in 5 yrs or the median survival of such patients, with: best supportive care only; optimal radiotherapy alone; optimal chemotherapy alone; or their previously recommended treatment. If they had not recommended radiotherapy combined with chemotherapy, they were asked what 5 yr survival rate or what median survival would have to be achieved in this type of patient for them to adopt such treatment routinely.

The third case history involved a $65 \mathrm{yr}$ old man with metastatic squamous cell cancer, the only symptom of which was minor haemoptysis: M1 disease. Respondents were asked whether they would recommend chemotherapy, and also whether they would recommend it if the patient was aged 50 yrs or younger. They were asked their views on either the probability of the patient being alive in $1 \mathrm{yr}$, or the median survival of such patients: with best supportive care only; or with optimal chemotherapy. If they had not recommended chemotherapy, they were asked what $1 \mathrm{yr}$ survival rate or what median survival would have to be achieved in this type of patient for them to adopt such treatment routinely.

The background information about respondents included their precise speciality, and how many new lung cancer patients they saw annually. Questions about their hospital included: number of beds; whether it had radiotherapy facilities; its region; and whether it was an undergraduate teaching hospital.

The questionnaire is shown in full in the Appendix.

\section{Results}

\section{Questionnaires returned}

A total of 821 questionnaires were sent out, and responses were obtained from 698 clinicians, giving a compliance rate of $85 \%$. However, 253 of the 698 replied that they did not treat patients with lung cancer or any patients covered by the survey. Of the remaining 445 clinicians in the survey: $220(49 \%)$ were respiratory physicians or general physicians with a special interest in respiratory medicine; $133(30 \%)$ radiotherapists; 59 (13\%) thoracic or cardiothoracic surgeons; 26 (6\%) medical oncologists; and 7 (2\%) palliative care physicians.

\section{Case 1: T2, N1, M0 disease}

Of the 445 clinicians, $372(84 \%)$ treated patients in this category. After successful resection, when the patient was well and symptom-free: $276(74 \%)$ of the clinicians would not recommend any adjuvant therapy; 91 (24\%) would recommend radiotherapy; $1(<1 \%)$ chemotherapy; and the remaining four (1\%) ticked the "Yes" box against "other therapy" and specified that they would recommend entry to a trial of adjuvant treatment or of prevention (European Respiratory Society Study on Cancer (EUROSCAN) trial). No clinician recommended multimodality treatment.

Clinicians' recommendations were very similar whatever their age, the number of new patients seen annually, the number of beds in their hospital, its region, and whether it had radiotherapy equipment or was involved in undergraduate teaching.

The clinicians' expectations of the patients' survival are presented in table 1 . Without adjuvant therapy, only $2 \%$ of clinicians who answered expected no chance of survival to $5 \mathrm{yrs}$; $44 \%$ expected a $1-20 \%$ chance of survival, and a further $41 \%$ a $21-40 \%$ chance. There was little, if any, expectation that adjuvant treatment of any sort could influence these probabilities, the figures for the various adjuvant therapy options being essentially the same as those for no adjuvant treatment.

It will be seen from table 1 that not all clinicians answered all sections of the question. However, of the 63 clinicians who did not answer the question for 
Table 1. - Case 1: clinicians' $(n=372)$ estimates of the probability of a patient being alive 5 yrs after successful surgical resection

\begin{tabular}{|c|c|c|}
\hline \multirow{2}{*}{$\begin{array}{l}\text { Probability of patients being } \\
\text { alive in } 5 \text { yrs } \%\end{array}$} & \multicolumn{2}{|c|}{ Clinicians } \\
\hline & $\mathrm{n}$ & $\%$ \\
\hline \multicolumn{3}{|l|}{ Without adjuvant therapy } \\
\hline 0 & 6 & 2 \\
\hline $1-20$ & 161 & 44 \\
\hline $21-40$ & 151 & 41 \\
\hline $41-60$ & 35 & 10 \\
\hline 61-80 & 9 & 2 \\
\hline $81-100$ & 3 & 1 \\
\hline NA & 7 & \\
\hline \multicolumn{3}{|l|}{ With adjuvant chemotherapy } \\
\hline 0 & 5 & 2 \\
\hline $1-20$ & 136 & 44 \\
\hline $21-40$ & 133 & 43 \\
\hline $41-60$ & 28 & 9 \\
\hline 61-80 & 4 & 1 \\
\hline $81-100$ & 3 & 1 \\
\hline NA & 63 & \\
\hline \multicolumn{3}{|l|}{ With adjuvant radiotherapy } \\
\hline 0 & 6 & 2 \\
\hline $1-20$ & 141 & 42 \\
\hline $21-40$ & 140 & 42 \\
\hline $41-60$ & 36 & 11 \\
\hline $61-80$ & 7 & 2 \\
\hline $81-100$ & 3 & 1 \\
\hline NA & 39 & \\
\hline \multicolumn{3}{|c|}{ With adjuvant chemotherapy and radiotherapy } \\
\hline 0 & 5 & 2 \\
\hline $1-20$ & 127 & 42 \\
\hline $21-40$ & 136 & 45 \\
\hline $41-60$ & 29 & 10 \\
\hline $61-80$ & 5 & 2 \\
\hline 81-100 & 3 & 1 \\
\hline NA & 67 & \\
\hline
\end{tabular}

The percentage values refer to those clinicians who answered the question. NA: not answered.

chemotherapy, none recommended it, of the 39 who did not answer for radiotherapy, only nine recommended it, and of the 67 who did not answer for combined treatment, only one recommended it.

In the hypothetical situation that a new combination of drugs had been developed as adjuvant treatment, those clinicians who had not recommended adjuvant chemotherapy (all but one of the 372) were asked what $5 \mathrm{yr}$ survival rate would have to be achieved by such treatment for them to adopt it routinely. Their responses are presented in table 2. In general, clinicians required substantial survival improvements with adjuvant chemotherapy for them to be prepared to recommend it routinely, $42 \%$ of the 266 who answered the question requiring an additional absolute benefit of more than $15 \%$.

Significantly more thoracic physicians than other clinicians would require adjuvant treatment to give more than $15 \%$ additional benefit in $5 \mathrm{yr}$ survival for them to adopt it routinely: 74 of $136(54 \%)$ compared with 39 of $130(30 \%)$, respectively ( $\mathrm{p}=0.001$, Chi-squared test).

\section{Case 2: T2, N3, MO disease}

Of the 445 clinicians, $416(93 \%)$ treated patients in this category. On discovering enlarged lymph nodes on both sides of the trachea in a patient in good condition (table 3): 281 (68\%) of the clinicians would recommend radiotherapy (64 with curative intent); 46 (11\%) chemo-
Table 2. - Case 1: improvement in 5 yr survival rates that would have to be achieved with adjuvant chemotherapy for clinicians to adopt such treatment routinely

\begin{tabular}{lcr}
\hline Additional benefit in 5 yr & \multicolumn{2}{c}{ Clinicians } \\
survival rate required $\%$ & \multicolumn{1}{c}{$\mathrm{n}$} & $\%$ \\
\hline $0-5$ & 32 & 12 \\
$6-10$ & 67 & 25 \\
$11-15$ & 54 & 20 \\
$16-20$ & 62 & 23 \\
$21-25$ & 21 & 8 \\
$26-100$ & 30 & 11 \\
NA & 105 & \\
\hline Total & 371 \\
\hline
\end{tabular}

The percentage values refer to those clinicians who answered the question. NA: not answered.

therapy; five (1\%) surgery; and $18(4 \%)$ ticked the "Yes" box against "other therapy", this then being specified as supportive care in 10, entry into a specified randomized trial in five, cryotherapy in one, steroids in one, and supportive care followed, if necessary, by radiotherapy in one. Among the clinicians who would recommend combinations of treatment modalities, one would recommend chemotherapy, radiotherapy and surgery, 26 chemotherapy and radiotherapy, and two radiotherapy and surgery. Three hundred and three $(73 \%)$ of the clinicians recommended at least one of the modalities, i.e. radiotherapy, chemotherapy or surgery. Radiotherapists were significantly less likely than other clinicians to recommend chemotherapy: 3 of $119(3 \%)$ compared with 43 of $250(17 \%)$, respectively $(\mathrm{p}<0.0001$, Chi-squared test). Recommendations were not influenced by other aspects of the clinicians or their hospitals.

The clinicians' expectations of patients' survival are presented in table 4 . Of the 416 clinicians, approximately half (200) expressed their expectations as $5 \mathrm{yr}$ survival rates, and the other half (216) as median survival (table 4). With best supportive care only, $42 \%$ of clinicians considered there was no chance of survival to $5 \mathrm{yrs}$, and a further $44 \%$ a chance of $\leq 5 \%$. For all forms of active treatment, their expectations were better and were broadly similar for the various treatment modalities. It is interesting to note that expectations were no greater for multimodality treatment using chemotherapy and radiotherapy than for either of these on their own. The findings expressed in terms of median survival showed a similar pattern.

Table 3. - Case 2: treatment recommended by clinicians $(n=416)$

\begin{tabular}{lrr}
\hline Treatment recommended & \multicolumn{2}{c}{ Clinicians } \\
& $\mathrm{n}$ & $\%$ \\
\hline Radiotherapy alone & 249 & 60 \\
Radiotherapy plus other & 32 & 8 \\
No radiotherapy & 135 & 32 \\
Chemotherapy alone* & 15 & 4 \\
Chemotherapy plus other & 31 & 7 \\
No chemotherapy & 370 & 89 \\
Surgery alone & 3 & 1 \\
Surgery plus other & 2 & $<1$ \\
No surgery & 411 & 99 \\
Other therapy alone & 17 & 4 \\
Other therapy combined & 1 & $<1$ \\
No other therapy & 394 & 95 \\
\hline
\end{tabular}

*: some stated for selected patients only. 
Table 4. - Case 2: clinicians' $(n=416)$ estimates of survival

\begin{tabular}{|c|c|c|c|c|c|}
\hline \multicolumn{3}{|c|}{$\begin{array}{l}\text { Estimation of percentage } \\
\text { alive in } 5 \text { yrs }\end{array}$} & \multicolumn{3}{|c|}{$\begin{array}{c}\text { Estimation of duration } \\
\text { of survival }\end{array}$} \\
\hline \multirow{2}{*}{$\begin{array}{l}\text { Probability } \\
\%\end{array}$} & \multicolumn{2}{|c|}{ Clinicians } & \multirow{2}{*}{$\begin{array}{l}\text { Median duration } \\
\text { months }\end{array}$} & \multicolumn{2}{|c|}{ Clinicians } \\
\hline & $\mathrm{n}$ & $\%$ & & $\mathrm{n}$ & \\
\hline \multicolumn{6}{|c|}{ With best supportive care only } \\
\hline 0 & 78 & 42 & 0 & 0 & \\
\hline $1-5$ & 81 & 44 & $1-6$ & 100 & 47 \\
\hline $6-10$ & 14 & 8 & $7-12$ & 101 & 47 \\
\hline $11-15$ & 2 & 1 & $13-18$ & 12 & \\
\hline $16-20$ & 7 & 4 & $\geq 19$ & 0 & 0 \\
\hline$\geq 21$ & 3 & 2 & & & \\
\hline NA & 15 & & NA & 3 & \\
\hline \multicolumn{6}{|c|}{ With optimal radiotherapy alone } \\
\hline 0 & 34 & 18 & 0 & 0 & 0 \\
\hline $1-5$ & 77 & 41 & $1-6$ & 49 & 23 \\
\hline $6-10$ & 51 & 27 & $7-12$ & 126 & 59 \\
\hline $11-15$ & 5 & 3 & $13-18$ & 26 & 12 \\
\hline $16-20$ & 9 & 5 & $\geq 19$ & 11 & 5 \\
\hline$\geq 21$ & 10 & 5 & & & \\
\hline NA & 14 & & NA & 4 & \\
\hline \multicolumn{6}{|c|}{ With optimal chemotherapy alone } \\
\hline 0 & 48 & 28 & 0 & 0 & \\
\hline $1-5$ & 79 & 46 & $1-6$ & 57 & 30 \\
\hline $6-10$ & 28 & 16 & $7-12$ & 108 & 56 \\
\hline $11-15$ & 2 & 1 & $13-18$ & 23 & 12 \\
\hline $16-20$ & 9 & 5 & $\geq 19$ & 4 & \\
\hline$\geq 21$ & 7 & 4 & & & \\
\hline NA & 27 & & NA & 24 & \\
\hline \multicolumn{6}{|c|}{ With optimal chemotherapy and radiotherapy } \\
\hline 0 & 29 & 17 & 0 & 0 & 0 \\
\hline $1-5$ & 66 & 39 & $1-6$ & 42 & 23 \\
\hline $6-10$ & 42 & 25 & $7-12$ & 100 & 55 \\
\hline $11-15$ & 10 & 6 & $13-18$ & 31 & 17 \\
\hline $16-20$ & 12 & 7 & $\geq 19$ & 10 & 5 \\
\hline$\geq 21$ & 9 & 6 & & & \\
\hline NA & 32 & & NA & 33 & \\
\hline \multicolumn{6}{|c|}{ With other treatment } \\
\hline 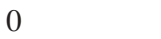 & 17 & 34 & 0 & 1 & 2 \\
\hline $1-5$ & 20 & 40 & $1-6$ & 15 & 30 \\
\hline $6-10$ & 9 & 18 & $7-12$ & 28 & 56 \\
\hline $11-15$ & 2 & 4 & $13-18$ & 5 & 10 \\
\hline $16-20$ & 1 & 2 & $\geq 19$ & 1 & 2 \\
\hline$\geq 21$ & 1 & 2 & & & \\
\hline NA & 150 & & NA & 166 & \\
\hline
\end{tabular}

The percentage values refer to those clinicians who answered the question. NA: not answered.

Those clinicians who did not currently recommend multimodality treatment with radiotherapy plus chemotherapy ( 389 of the 416) were asked what survival rate or median survival would have to be achieved for them to adopt this treatment routinely. Their responses in terms of additional benefit required are presented in table 5. Of the 183 clinicians who answered in terms of 5 yr survival rates, the majority would want to see substantial survival improvements with a new combination of chemotherapy and radiotherapy before recommending it routinely; $43 \%$ of the 134 who responded required an absolute improvement of more than $15 \%$. In contrast, the requirements of the 206 clinicians who answered in terms of median survival were more modest; but even in this group, $37 \%$ of the 153 who responded required an improvement of more than $10 \%$ (10\% requiring an improvement of more than 15\%). The responses by clinical speciality were similar (data not shown).
Table 5. - Case 2: improvement in $5 \mathrm{yr}$ and median survival rates that would have to be achieved with adjuvant chemotherapy for clinicians to adopt such treatment routinely

\begin{tabular}{lcrrr}
\hline Additional & \multicolumn{2}{c}{ Clinicians using } & \multicolumn{2}{c}{} \\
benefit required & \multicolumn{2}{c}{5 yr survival } & \multicolumn{2}{c}{ Median survival } \\
$\%$ & n & $\%$ & \multicolumn{1}{c}{ n } & $\%$ \\
\hline $0-5$ & 11 & 8 & 39 & 25 \\
$6-10$ & 36 & 27 & 57 & 37 \\
$11-15$ & 29 & 22 & 41 & 27 \\
$16-20$ & 30 & 22 & 10 & 6 \\
$21-25$ & 11 & 8 & 4 & 3 \\
$\geq 26$ & 17 & 13 & 2 & 1 \\
NA & 49 & & 53 & \\
\hline Total & 183 & & 206 & \\
\hline
\end{tabular}

The percentage values refer to those clinicians who answered the question. NA: not answered.

\section{Case 3: M1 disease}

Of the 445 clinicians, $423(95 \%)$ treated patients in this category. On detecting metastases in a $65 \mathrm{yr}$ old patient in good condition, only $46(11 \%)$ clinicians would recommend chemotherapy, although 111 (26\%) would do so for an otherwise similar patient aged $\leq 50 \mathrm{yrs}$. The great majority, 298 (70\%), would not recommend chemotherapy for either patient. Radiotherapists were again less likely than other clinicians to recommend chemotherapy: two of 130 (2\%) compared with 44 of 289 $(15 \%)$, respectively $(\mathrm{p}<0.0001$, Chi-squared test). Smaller centres (treating $<50$ patients annually) were more likely than larger centres to recommend chemotherapy $(\mathrm{p}=$ 0.06 for $65 \mathrm{yr}$ olds; $\mathrm{p}=0.001$ for patients aged $\leq 50 \mathrm{yrs}$, Mann-Whitney test). Recommendations were not influenced by other aspects of the clinicians or their hospitals.

The clinicians' expectations of patients' survival are presented in table 6 . Of the 423 clinicians, 208 expressed their expectations as $1 \mathrm{yr}$ survival rates (table 6a), and 215 as median survival (table 6b). With best supportive care only, $18 \%$ of clinicians considered there was no chance of survival to $1 \mathrm{yr}$, and a further $56 \%$ a chance of $\leq 10 \%$. Their expectations were no better for optimal chemotherapy, the equivalent percentages being 13 and $54 \%$. In contrast, among the clinicians expressing their expectations in terms of median survival, only $24 \%$ would have expected a median survival of $\geq 7$ months with best supportive care only, but $42 \%$ with optimal chemotherapy.

Those clinicians who did not currently recommend chemotherapy (377 of the 423) were asked what $1 \mathrm{yr}$ survival rate or median survival would have to be achieved by a new combination of drugs for them to adopt such new treatment routinely. Their responses in terms of additional benefit required are presented in table 7 . Of the 181 clinicians who answered in terms of $1 \mathrm{yr}$ survival rates, $43 \%$ would want to see an absolute improvement of more than $15 \%$. As for Case 2, the requirements of the clinicians who answered in terms of median survival were more modest: $26 \%$ of the 176 who responded would want to see an improvement of more than $10 \%$ (13\% requiring an improvement of more than $15 \%)$. The responses by clinical speciality were similar (data not shown). 
Table 6. - Case 3: clinicians' $(n=423)$ estimates of survival

\begin{tabular}{|c|c|c|}
\hline \multirow[t]{2}{*}{ Clinicians' estimate } & \multicolumn{2}{|c|}{ Clinicians } \\
\hline & $\mathrm{n}$ & $\%$ \\
\hline \multicolumn{3}{|c|}{$\begin{array}{l}\text { a) Probability of patient being alive in } 1 \mathrm{yr} \% \\
\text { With best supportive care only }\end{array}$} \\
\hline 0 & 35 & 18 \\
\hline $1-10$ & 109 & 56 \\
\hline $11-20$ & 28 & 14 \\
\hline $21-30$ & 11 & 6 \\
\hline $31-40$ & 6 & 3 \\
\hline$\geq 41$ & 7 & 4 \\
\hline NA & 12 & \\
\hline \multicolumn{3}{|c|}{ With optimal chemotherapy } \\
\hline 0 & 24 & 13 \\
\hline $1-10$ & 103 & 54 \\
\hline $11-20$ & 36 & 19 \\
\hline $21-30$ & 9 & 5 \\
\hline $31-40$ & 8 & 4 \\
\hline$\geq 41$ & 12 & 6 \\
\hline NA & 16 & \\
\hline \multicolumn{3}{|c|}{ b) Expected median survival months } \\
\hline \multicolumn{3}{|c|}{ With best supportive care only } \\
\hline 0 & 0 & 0 \\
\hline $1-6$ & 161 & 75 \\
\hline $7-12$ & 41 & 19 \\
\hline $13-18$ & 8 & 4 \\
\hline 19-24 & 1 & $<1$ \\
\hline$\geq 25$ & 0 & 0 \\
\hline NA & 4 & \\
\hline \multicolumn{3}{|c|}{ With optimal chemotherapy } \\
\hline 0 & 1 & $<1$ \\
\hline $1-6$ & 117 & 57 \\
\hline $7-12$ & 73 & 36 \\
\hline $13-18$ & 9 & 4 \\
\hline 19-24 & 3 & 1 \\
\hline$\geq 25$ & 2 & 1 \\
\hline NA & 10 & \\
\hline
\end{tabular}

The percentage values refer to those clinicians who answered the question. NA: not answered.

Table 7. - Case 3: improvement in survival rates that would have to be achieved with chemotherapy for clinicians to adopt it routinely

\begin{tabular}{lcrrr}
\hline $\begin{array}{l}\text { Additional } \\
\text { benefit required }\end{array}$ & \multicolumn{2}{c}{$\begin{array}{c}\text { Clinicians using } \\
\text { 1 yr survival }\end{array}$} & \multicolumn{2}{c}{ Median } \\
$\%$ & n & $\%$ & n & $\%$ \\
\hline $0-5$ & 13 & 9 & 48 & 27 \\
$6-10$ & 42 & 28 & 83 & 47 \\
$11-15$ & 31 & 21 & 23 & 13 \\
$16-20$ & 34 & 23 & 14 & 8 \\
$21-25$ & 8 & 5 & 3 & 2 \\
$\geq 26$ & 22 & 15 & 5 & 3 \\
NA & 31 & & 20 & \\
\hline Total & 181 & & 196 & \\
\hline
\end{tabular}

The percentage values refer to those clinicians who answered the question. NA: not answered.

\section{Discussion}

This survey provides a comprehensive assessment of the attitudes of consultants in England and Wales towards the treatment of lung cancer. It is notable both for the degree of conservatism towards the use of radiotherapy and chemotherapy, and for the large increase in survival that the respondents would require to change their prac- tice. The meta-analysis indicated that such large improvements in survival were unlikely. However, patients' priorities may be different. Substantial proportions of patients who know they have cancer are willing to accept intensive, potentially toxic chemotherapy or chemoradiotherapy for a small chance of a modest survival benefit $[14,15]$.

The survey comes at a time when there is increasing interest in the use of chemotherapy in all stages of NSCLC. The patient data-based meta-analysis has suggested a small benefit in long-term survival for stage I-III disease, and in median and 2 yr survival for metastatic disease [12]. The benefit, however, from these admittedly heterogeneous randomized trials is only $2-10 \%$. This is considerably smaller than the respondents' stated requirements to change their policy of treatment. More recent small-scale trials of operable cases [16, 17], and of chemotherapy given as neoadjuvant treatment before radiotherapy [18], suggest that larger improvements in survival may be possible. Furthermore, attitudes stated before the results of recent studies, including the meta-analysis, were known, may not be inflexible. In cancers of the breast and colon, large trials and metaanalyses showing that small but definite survival benefits can be achieved by chemotherapy, have greatly influenced attitudes to treatment. The same change in perception of the value of small benefits in survival may occur in NSCLC if a survival benefit could be clearly shown. Indeed, the survey itself indicates that this might occur, since a substantial minority of respondents were unsure how to answer the question on possible changes in survival attributable to chemotherapy or radiotherapy, and $26 \%$ stated that they would use chemotherapy for younger patients with advanced disease.

The results emphasize the need for large-scale randomized trials, where the survival benefit, if any, can be more precisely measured, and where costs can be analysed. A recent study in Canada has indicated that costs are reduced for some chemotherapy regimens compared with best supportive care [19], a result which, if confirmed and more widely known, might well influence attitudes in the UK. The easily defined costs of chemotherapy and radiotherapy, compared with the less obvious costs of supportive care, may bias judgement about the economic consequences of treatment. This may create difficulties in systems of health care where purchasers can refuse payment for treatments that are deemed to be of poor value. Such purchasers may not be sufficiently knowledgeable to make judgements about benefit.

It is of interest to compare the results reported here with those of the parallel Canadian survey [13]. The Canadian results were derived from a proportion of the respondents, such that there were equal proportions of chest physicians, thoracic surgeons, medical oncologists, and radiation oncologists. There was, however, little systematic difference in response between specialities in the present survey, and so comparisons between the findings in England and Wales and in Canada can reasonably be made.

For Case 1 (T2, N1, M0), the predictions of survival after surgery showed a very similar distribution in the two surveys, with a broad scatter about the mean. In both surveys, chemotherapy was felt to add little to survival. 
The greater proportion of consultants in England and Wales who did not answer the question about the possible benefit of adjuvant radiotherapy and chemotherapy, may indicate a substantial measure of uncertainty about the results of treatment trials.

For Case 2 (T2, N3, M0), 65\% of Canadian respondents recommended radiation treatment for this stage IIIb tumour, compared with $68 \%$ of consultants in England and Wales. In Canada, $70 \%$ believed that additional chemotherapy would not prolong survival. This was generally true in the present survey, although a small proportion $(7 \%)$ of respondents thought that there might be a benefit in $5 \mathrm{yr}$ and median survival. In England and Wales, $35 \%$ of respondents would use chemotherapy if the $5 \mathrm{yr}$ survival was increased by up to $10 \%$, the majority demanding much larger improvements. However, $62 \%$ of respondents would use chemotherapy for less than $10 \%$ improvement in median survival. It is notable that $26 \%$ did not answer this question, and that thoracic physicians were more demanding of improvement than oncologists. In Canada, the doctors who recommended chemotherapy judged that median survival would increase by 4.1 months, while those who did not, judged the increase to be 0.25 months. Values for benefit in $5 \mathrm{yr}$ survival were 6 and $0.3 \%$, respectively, judgements very similar in degree and variability to those in England and Wales.

Consultants in England and Wales anticipated little or no benefit in $1 \mathrm{yr}$ or median survival from chemotherapy in Case 3 (M1), compared with best supportive care. Canadian clinicians were somewhat less negative, although $42 \%$ judged that no benefit would accrue and a further $30 \%$ estimated the improvement in median survival to be less than 2 months. In England and Wales, $28 \%$ of respondents would require an additional $6-10 \%$ survival at $1 \mathrm{yr}$ to use chemotherapy routinely, but $47 \%$ would give drug treatment if median survival increased by $6-10 \%$. Since $75 \%$ expected median survival to be 1-6 months with best supportive care only, this increase would be only 2-4 weeks.

In conclusion, the results of the two surveys show striking similarities, characterized by widely differing levels of expectation of outcome, and little anticipation of benefit from radiotherapy or chemotherapy in any of the three clinical settings presented. Although the routine use of chemotherapy and radiotherapy would apparently only be adopted if relatively large survival benefits accrued, it is possible that this reflects uncertainty as to the true benefits, since clinical trials of treatment with radiotherapy or chemotherapy have given widely differing results. A greater uniformity of view might result if several very large trials gave a more precise estimate of benefit. While such benefit has been suggested for chemotherapy in the recent meta-analysis, a similar analysis has not been performed for radiotherapy. The heterogeneity of treatments in such analyses means, in any event, that they are not, in non-small cell lung cancer, a substitute for very large-scale studies.

Acknowledgement: The authors thank all the clinicians who collaborated in this survey, thereby providing a very high compliance rate and correspondingly reliable data.

\section{Appendix}

\section{TREATMENT OF NON-SMALL CELL LUNG CANCER: A NATIONAL SURVEY}

This survey has been designed to cover several important aspects of the treatment of non-small cell lung cancer (NSCLC). If you think one or more of the cases presented here is not relevant to your practice, please let us know by ticking the box immediately after the description of each case.

This questionnaire is being sent to all consultant radiotherapists, medical oncologists, cardiothoracic surgeons, thoracic physicians, general physicians with a special interest in thoracic medicine and physicians of palliative medicine in England and Wales.

Case 1: A 65 yr old man presents to you complaining of two minor episodes of haemoptysis and he has no other symptoms. There is a $4 \mathrm{~cm}$ diameter mass in the right lower lobe on chest radiography. A bronchoscopy and biopsy confirm the diagnosis of a squamous cell carcinoma. A full metastatic work-up is negative. At surgery, a microscopically positive right hilar node is found but all the other nodes are negative. A right pneumonectomy is performed and the resection is considered complete both macroscopically and microscopically. Following surgery, the patient comes back for a followup visit. He has no symptoms and he is doing well (T2, N1, M0 patient).

If you are never involved in the care of patients in this situation, tick the box and go to Case 2. Otherwise, answer the questions below which are not mutually exclusive. (Equivalent questions, not repeated, appeared after the descriptions of Cases 2 and 3.)

At this point, would you recommend: adjuvant chemotherapy? Yes/No; adjuvant radiotherapy? Yes/No; other therapy? Yes/No, if "yes", specify.

In your opinion, what is the probability of this patient being alive in 5 yrs: without adjuvant therapy?; with adjuvant chemotherapy?; with adjuvant radiotherapy?; with adjuvant chemotherapy and radiotherapy?

If you currently recommend adjuvant chemotherapy for patients such as Case 1, skip the following question and go to Case 2. Otherwise, answer the question below. (Equivalent questions, not repeated, appeared in the appropriate place under Cases 2 and 3.)

Suppose that a new combination of drugs has been developed as adjuvant treatment for resected stage II NSCLC and that the toxicity of this combination has been similar to that of current chemotherapy (e.g. vindesine and platinum): what $5 \mathrm{yr}$ survival rate would have to be achieved in this group of patients in order for you to adopt this treatment routinely?

Case 2: A $4 \mathrm{~cm}$ mass in the left upper lobe with mediastinal widening is found on routine chest radiography of an asymptomatic $65 \mathrm{yr}$ old man. At mediastinoscopy, enlarged lymph nodes involved with squamous carcinoma are found on both sides of the trachea. The rest of the metastatic work-up is negative. The patient is in good condition and willing to follow any of your recommendations (T2, N3, M0 patient).

At this point, would you recommend: thoracic radiotherapy? Yes/No, if "yes", specify, if you wish, palliative or curative; chemotherapy? Yes/No, if "yes", specify, if you wish; surgery? Yes/No, if "yes", specify if you wish; other therapy? Yes/No, if "yes", specify. 
Which measure of outcome do you prefer as an estimate of the value of treatment for stage IIIb NSCLC?: 5 yr survival rate, or median survival.

If you have chosen the $5 \mathrm{yr}$ survival rate from the previous question, continue with the questions on this page. If you have chosen the median survival from the previous question, go to page $\mathrm{x}$. (On page $\mathrm{x}$, the following questions were framed around median instead of $5 \mathrm{yr}$ survival; they are not reproduced here.)

In your opinion, what is the probability of this patient being alive in 5 yrs: with best supportive care only?; with optimal radiotherapy alone?; with optimal chemotherapy alone?; with optimal chemotherapy and radiotherapy?; with the treatment that you recommended earlier for this patient, if this has not been described in this section?

Suppose that a new combination of drugs combined with "curative" radiotherapy has been developed for the treatment of stage IIIb NSCLC and that the toxicity of this combination has been similar to that of current chemotherapy (e.g. vindesine and platinum) given in addition to radiation: what $5 \mathrm{yr}$ survival rate would have to be achieved in this group of patients in order for you to adopt this treatment routinely?

Case 3: A $65 \mathrm{yr}$ old man presents to you complaining of minor haemoptysis and no other symptoms. His chest radiograph shows a $4 \mathrm{~cm}$ mass in the right upper lobe. A bone scintigram shows two areas of increased uptake in his right humerus and one in his skull. A biopsy of the humerus reveals squamous cell carcinoma. The rest of the metastatic work-up is negative. The patient is in good condition and willing to follow any of your recommendations (M1 patient).

Would you recommend chemotherapy for this patient? Yes/No; for a similar patient aged 50 yrs or younger? Yes/No.

Which measure of outcome do you prefer as an estimate of the value of treatment for stage IV (metastatic) NSCLC?: 1 yr survival rate, or median survival.

In your opinion, what is the probability of this patient being alive in $1 \mathrm{yr}$ : with best supportive care only?; with optimal chemotherapy?

Suppose that a new combination of drugs has been developed for treatment of stage IV (metastatic) NSCLC and that the toxicity of this combination has been similar to that of current chemotherapy (e.g. vindesine and platinum): what $1 \mathrm{yr}$ survival rate would have to be achieved in this group of patients in order for you to adopt this treatment routinely?

You, your training and your practice: Your age. Your gender. From which medical school did you obtain your medical qualification?, your speciality training? Which one best describes your practice: respirologist/thoracic physician; thoracic surgeon; radio-oncologist; medical oncologist; internist; haematological oncologist; other (specify)? On average, how many new lung cancer patients do you see per year? What proportion of all the patients with lung cancer that you see have been referred to you by another specialist (as opposed to referral by a general practitioner or a family doctor or to a patient who consulted you directly)? How many beds are there in the hospital where you practise? Is there radiotherapy equipment in it? In which region is the hospital where you practise located? Is it an undergraduate teaching hospital? What percentage of your working time is devoted to the following tasks?: teaching; administration; clin- ical work; research; other. Which approach best describes your attitude when a decision has to be made for treatment of a patient with metastatic lung cancer?: I recommend the treatment I think best for the patient; I describe the different kinds of treatment available and I recommend the best for the patient; I describe different possible treatments to the patient and she/he makes a final choice of treatment.

\section{References}

1. Watanabe Y, Shimizu J, Oda M, et al. Aggressive surgical intervention in N2 non-small cell cancer of the lung. Ann Thorac Surg 1991; 51: 253-261.

2. Souhami RL. Current issues in cancer: lung cancer. BMJ 1992; 304: 1298-1301.

3. Tsang GMK, Watson DCT. The practice of cardiothoracic surgeons in the perioperative staging of non-small cell lung cancer. Thorax 1992; 47: 3-5.

4. Muers MF. Preoperative screening for metastases in lung cancer. Thorax 1994; 49: 1-2.

5. Carroll M, Morgan SA, Yarnold JR, Hill JM, Wright NM. Prospective evaluation of a watch policy in patients with inoperable non-small cell lung cancer. Eur J Cancer Clin Oncol 1986; 22: 1353-1356.

6. Macbeth FR, Bolger J. Palliative radiotherapy for bronchial carcinoma: science or art? Clin Oncol 1991; 3: 245-246.

7. Aisner J, Belani CP. Lung cancer: recent changes and expectations of improvements. Semin Oncol 1992; 20: 383-393.

8. Johnson DH. Chemotherapy for stage III non-small cell lung cancer. Lung Cancer 1994; 11 (Suppl. 2): 148-150.

9. Talbot DC, Smith IE. New drugs in lung cancer. In: Thatcher N, Spiro S, eds. New Perspectives in Lung Cancer. London, British Medical Journal Publishing Group, 1994; pp. 143-160.

10. Report of a Working Group to the Standing Medical Advisory Committee (Department of Health). The management of lung cancer: current clinical practices, 1994.

11. Smith IE. Palliative chemotherapy for advanced nonsmall cell lung cancer: time to reappraise its role. $B M J$ 1994; 308: 429-430.

12. Non-small Cell Lung Cancer Collaborative Group. Chemotherapy in non-small cell lung cancer: a metaanalysis using updated data on individual patients from 52 randomised clinical trials. BMJ 1995; 311: 899-909.

13. Raby B, Pater J, Mackillop WJ. Does knowledge guide practice? Another look at the management of non-small cell lung cancer. J Clin Oncol 1995; 13: 1904-1911.

14. Slevin ML, Stubbs L, Plant HJ, et al. Attitudes to chemotherapy: comparing views of patients with cancer with those of doctors, nurses, and general public. $B M J$ 1990; 300: 1458-1460.

15. Brundage MD, Davidson JR, Mackillop WJ. Trading treatment toxicity for survival in locally advanced nonsmall cell lung cancer. J Clin Oncol 1997; 15: 330-340.

16. Rosell R, Gómez-Codina J, Camps C, et al. A randomized trial comparing preoperative chemotherapy plus surgery with surgery alone in patients with non-small cell lung cancer. N Engl J Med 1994; 330: 153-158.

17. Roth JA, Fossella F, Komaki R, et al. A randomized trial comparing perioperative chemotherapy and surgery with surgery alone in resectable stage IIIA non-small cell lung cancer. J Natl Cancer Inst 1994; 86: 673-680.

18. Le Chevalier T, Arriagada R, Quoix E, et al. Radiotherapy alone versus combined chemotherapy and radiotherapy in nonresectable non-small cell lung cancer: first analysis of a randomized trial in 353 patients. J Natl Cancer Inst 1991; 83: 417-423.

19. Evans WK, Will BP, Berthelot J-M, Wolfson M. Diagnostic and therapeutic approaches to lung cancer in Canada and their costs. Br J Cancer 1995; 72: 1270-1277. 